\title{
Erratum to: Effectiveness of copula-extreme value theory in estimating value-at-risk: empirical evidence from Asian emerging markets
}

\author{
Chun-Pin Hsu $\cdot$ Chin-Wen Huang • Wan-Jiun Paul Chiou
}

Published online: 18 April 2012

(C) Springer Science+Business Media, LLC 2012

\section{Erratum to: Rev Quant Finan Acc DOI 10.1007/s11156-011-0261-0}

The affiliation of the co-author (Wan-Jiun Paul Chiou) is hereby replaced with the following: Department of Finance and Law, Central Michigan University, Mount Pleasant, MI 48859, USA, wpchiou@gmail.com.

The online version of the original article can be found under doi:10.1007/s11156-011-0261-0.

C.-P. Hsu ( $\square)$

Department of Accounting and Finance, York College, The City University of New York, 94-20 Guy R. Brewer Blvd, Jamaica, NY 11451, USA

e-mail: chsu@york.cuny.edu

C.-W. Huang

Finance Department, Western Connecticut State University, Danbury, CT, USA

e-mail: huangc@wcsu.edu

W.-J. P. Chiou

Department of Finance and Law, Central Michigan University, Mount Pleasant, MI 48859, USA

e-mail:wpchiou@gmail.com 